\title{
Tratamiento hormonal en el homosexualismo de origen suprarrenal
}

\author{
Profesor Pedro Nel Cardona \\ Doctor Fernando Cardona Arango
}

Nos parece oportuno, con el fin de precisar conceptos, el exponer el metabolismo de las hormonas suprarrenales tal como lo concibe el doctor Francisco Vivanco Bergamin, del Instituto de Investrgaciones Clínicas y Médicas de Madrid (1). Queremos resaltar el hecho de que este trabajo ha sido efectuado gracias al alto espíritu científico, al real concepto de la fraternidad médica y a la

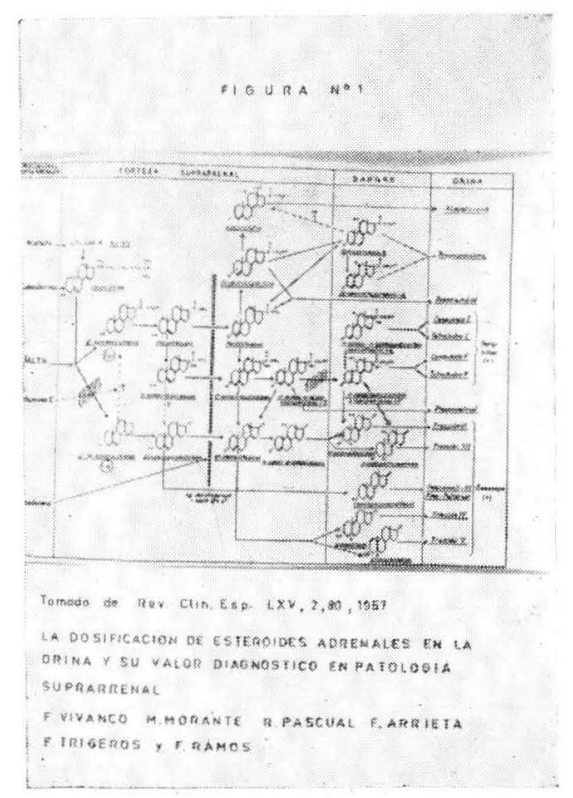

FIGURA NUMERO 1 
eievada conciencia hispanoamericana del doctor vivanco, quien enseñó a uno de nosotros el presente metabolismo de los esteroides suprarrenales y las técnicas de dosificaciones hormonales que relatamos más adelante.

Como puede apreciarse en la figura número 1, cuando hay un trastorno enzimático de la 3 beta dehidrogenasa, no se efectúa el salto de Delta 5 a Delta 4 y por consiguiente la dehidroisoandros. terona no se metabolizará a Delta 4 androstenediona, que es la precursora de varias hormonas, entre ellas la androsterona y la etiocolanolona. Por lo tanto este trastorno enzimático traerá como consecuencia una elevación en el porcentaje circulante de la dehidroisoandrosterona y una disminución de la androsterona y la etiocolanolona de origen suprarrenal.

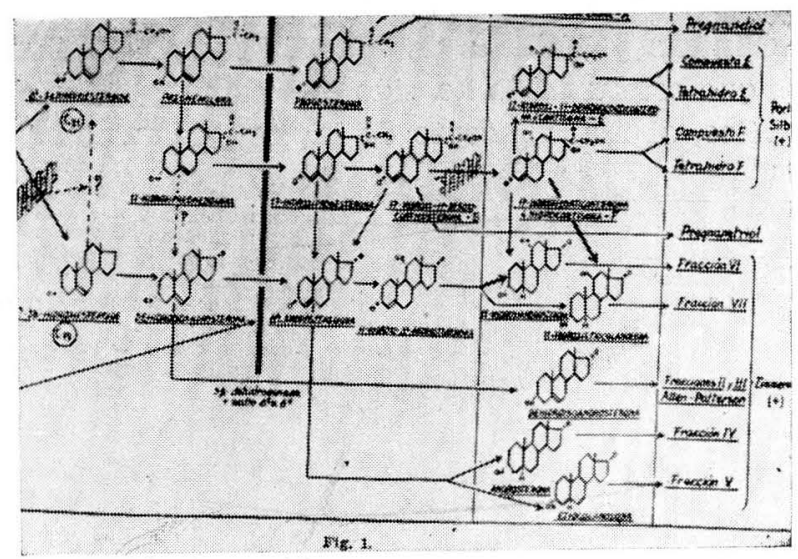

FIGURA NUMERO 1-A

Sabemos que la etiocolanolona no posee prácticamente acción androgénica; en cambio sí la dehidroisoandrosterona (2), por lo tanto habrá una mayor actividad androgénica suprarrenal cuando este trastorno se presenta y como consecuencia habrá un freno mayor hipofisiario en cuanto a las hormonas gonadotropas y una mayor producción de A C T H para compensar la falta de las hormonas procedentes de la androstenediona. 
Lo anterior lo representamos esquemáticamente así:

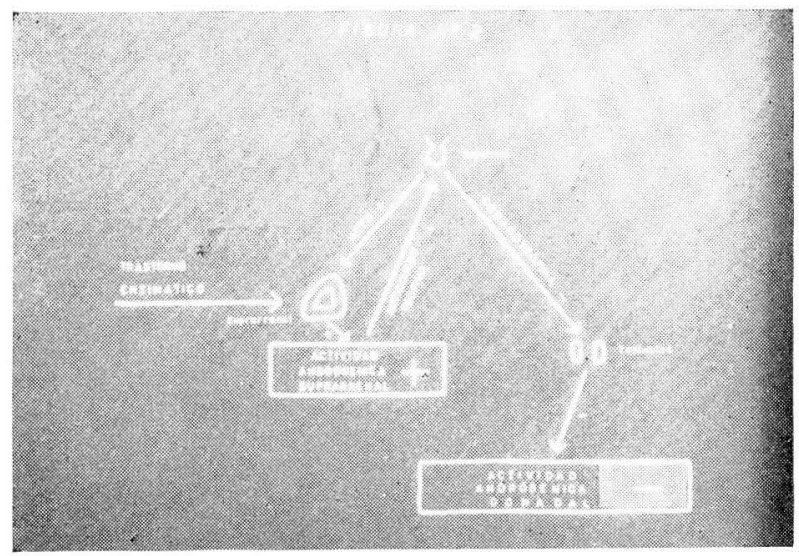

FIGURA NUMERO ?

La causa íntima del trastorno enzimático la desconocemos, por lo tanto para poder cambiar el estado hormonal repreisentado en ia figura número 2, necesitamos recurrir a una terapéutica que trate de suplir los metabolismos de, la Delta 4 androstenediona que se encuentran en bajo porcentaje, y que a la vez frene la hipersecreción del A C T H (3) para que en forma compensadora aumenten las gonadotropinas. Esto lo podemos lograr administrando prednisona (1 dehidro-cortisona) y lo podemos representar Esquemáticamente așí (figura número 3 ):

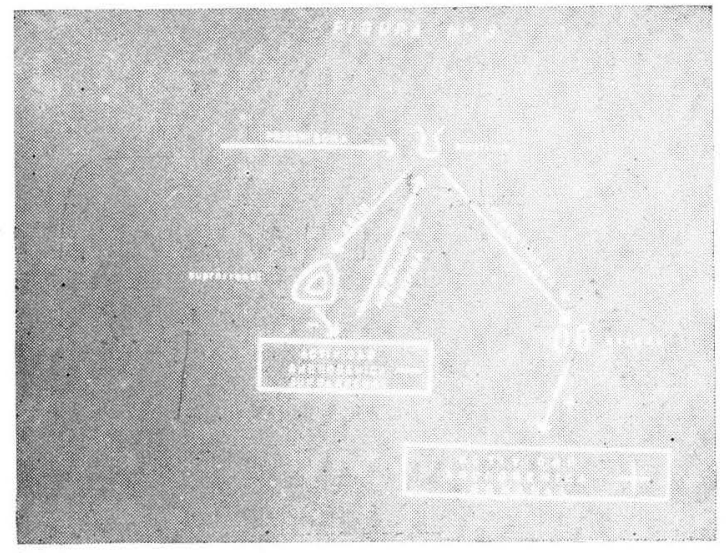

FIGURA NUMERO 3 


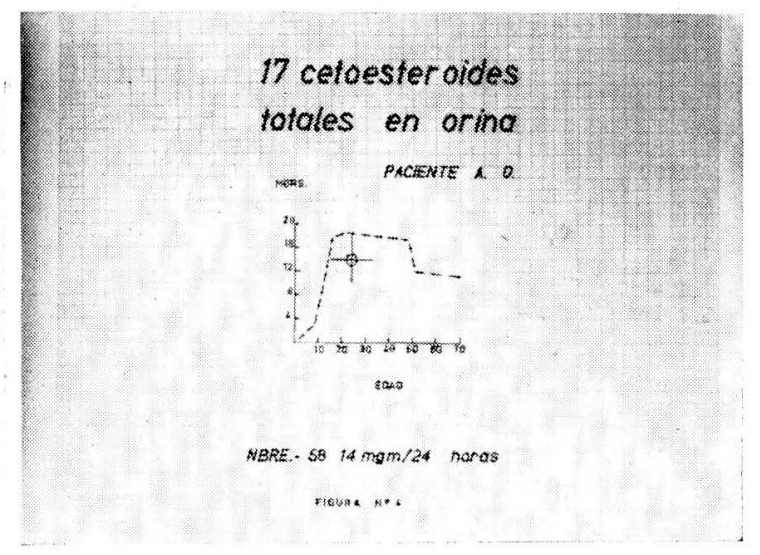

\section{FIGURA NUMERO 4}

Comparando la figura número 3 con la número 2 vemos que el efecto hormonal en esta última es inverso al anterior, quedándonos en esta forma resuelto el problema.

Nuestra escasa pero significativa experiencia nos enseña que un tratamiento de dos meses con prednisona, resuelve el problema hormonal por un mínimo de seis meses, y decimos mínimo de seis meses, pues éste es el tiempo que llevamos observando el caso cuya historia clínica presentamos.

Enfermo A. O., de veinticuatro años, que consulta por homosexualismo; la anamnesis nos revela que principió sus relaciones heterosexuales a los catorce años con una frecuencia de una vez por semana por encontrarse en un internado; así continuó hasta los dieciséis años; a los diecinueve años consiguió una amante y la frecuencia pasó a ser diaria con períodos de 5 a 6 veces en la noche; a los veinte y veintiún años sus relaciones sexuales disminuyeron en frecuencia hasta el punto de ser una o dos veces al mes; a los veintidós y veintitrés años notó que la libido decaía en forma progresiva hasta seis meses antes de venir a la consulta en cue sus deseos se tornaron en franco homosexualismo.

El examen físico nos revela unos genitales externos normales y una hipertricosis moderada tipo masculino. La dosificación de los 17 cetoesteroides totales en la orina según la técnica de Drekter y colaboradores (4), nos da en la diuresis de 24 horas un total de 14 miligramos, cifra 4 miligramos por debajo de la media normal (5) (Figura número 4). 


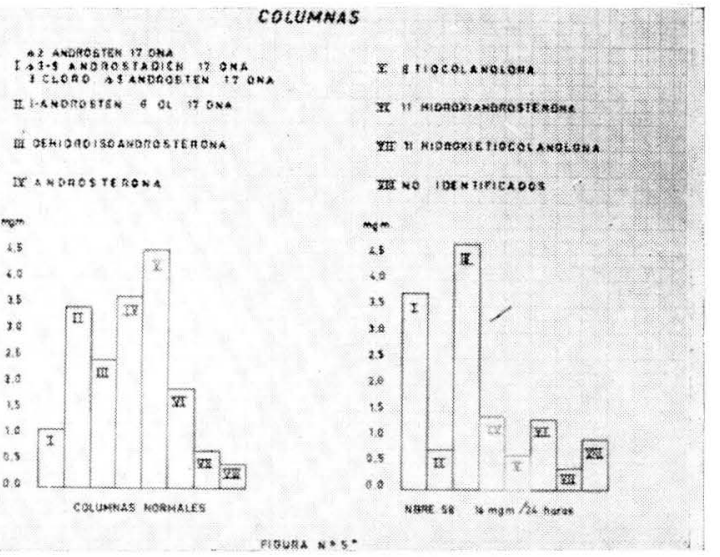

FIGURA NUMERO 5

La dosificación de los 17 cetoesteroides urinarios separados por cromatografía según técnica de la doctora Dingemanse y colaboradores (6), nos revela un muy acentuado aumento en las coiumnas I y III, ambas de origen suprarrenal, y una significativa disminución de la IV y la V que son de origen gonadal (Figura nú. mero 5).

El estudio de la figura número 5 nos revela una imagen hormonal como la expresada gráficamente en la figura número 2.

Tratamos al paciente con prednisona a la dosis de 5 miligramos cada 12 horas durante 2 meses, buscando un resultado como el expresado en la figura número 3; luego continuamos el tratamiento en forma decreciente durante cuatro semanas.

A los dos meses de terminada la terapéutica obtenemos una cifra de 7.8 miligramos de 17 cetoesteroides totales en la diuresis de 24 horas, es decir, una disminución de 6.2 miligramos con respecto a la dosificación efectuada antes de iniciar el tratamiento. (Figura número 6).

La cromatografía de las hormonas 17 cetoesteroides efectuada a los 2 meses de terminado el tratamiento nos muestra al compararla con la realizada antes de iniciar la terapéutica con predrisona, un descenso apreciable de 2.7 miligramos en la I y $3.4 \mathrm{mi}-$ iigramos en la III y un aumento significativo de 0.8 miligramos en la V (Figura número 7). 


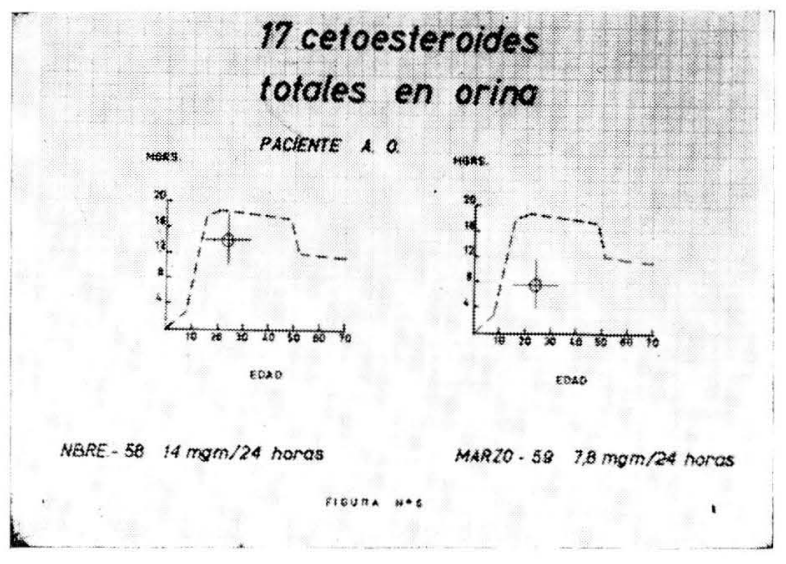

FIGURA NUMERO 6

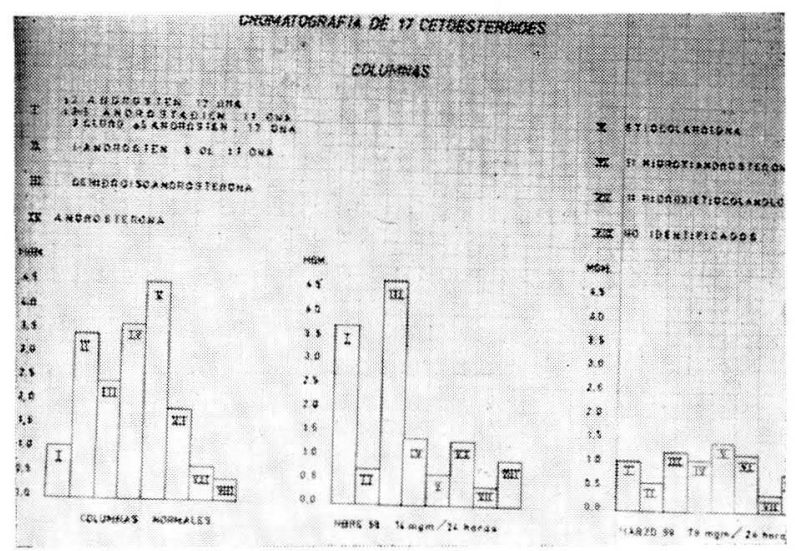

FIGURA NUMERO 7

Simultáneamente con la última dosificación el paciente nos informa su evolución homosexual hacia la heterosexual y así se encuentra actualmente, 6 meses después de iniciado el tratamiento.

Basados en los hallazgos hormonales de antes y después de la administración de prednisona, nos creemos autorizados para sacar las siguientes conclusiones:

1) Hay homosexualismo de origen suprarrenal.

2) Estos casos pueden ser diagnosticados por cromatografía de 17 cetoesteroides en la orina.

3) Los casos de homosexualismo de origen suprarrenal pue. den ser tratados hormonalmente.

Carrera 46, número 52-95. - Medellín, Colombia. 


\section{BIBLIOGRAFIA}

1. VIVANCO F. MORANTE M., PASCUAL R., ARRIETA F. TRIGUEROS F. RAMOS F.- La dosificación de esteroides adrenales en la orina y su valor diagnóstico en patología suprarrenal. Rev. Clin. Esp. LXV, 2, 80. 1957.

2. PASCHKIS K. E., RAKOFF A. E. y CANTAROW A.-Endocrinología Clínica. Edit. Interamericana. México. Página 235. 1954.

3. BAULIEU E. E.-Les Hypercorticismes surrénaliens. Masson y Cía. Ed. París. Página 18. 1958.

4. DREKTER I. J., PEARSON S., BARTCKZAR E. y MC GAVACK T. H. Determinación de los 17 cetoesteroides totales en la orina de 24 horas. J. Clin. Endocrinol. 7, 795. 1947.

5. ALBEAUX-FERNET M. y COL.-Les corticostéroides urinaires dans l'exproration de la fonction certico-surrénale. L'Année Endocrinologique. Masson y Cía. Ed. París. 1956. Páginas 69, 95.

6. DINGEMANSEE E., HUIS IN'T VELD Y HARTOGH-KATZ S. L.-Cromatografía de esteroides urinarios en columna. Clin. Endocrinol. 12, 1, 1952. $66-85$. 